\title{
Measuring Progress on Climate Change Adaptation Policy by Dutch Water Boards
}

\author{
Hans Kamperman ${ }^{1} \cdot$ Robbert Biesbroek $^{2}$ (D)
}

Received: 29 March 2017 / Accepted: 19 June 2017 /

Published online: 7 July 2017

(C) The Author(s) 2017. This article is an open access publication

\begin{abstract}
The Netherlands is particularly vulnerable for the impacts of climate change on the water system. Regional water authorities, or water boards, are given an important role to design and implement specific adaptation policies and measures to manage these impacts. From the early 2000 s onwards water boards are starting to adapt to climate change impacts, yet no systematic assessments exist to assess whether or not progress is being made and what explains similarities and differences across water boards. This paper aims to address these critical questions by analyzing the progress of all Dutch water boards for the period 2005-2016. We systematically collected and analyzed three consecutive water management plans for all 23 water boards in the Netherlands. We use content analysis methods to analyze progress by looking into their vulnerability and three levels of adaptation: recognition, groundwork and adaptation action. The results show that over time the number of reported climate change adaptation initiatives by the water boards is increasing, but most climate change adaptation is still at the recognition or groundwork level. Our findings reveal a diversity of efforts to adapt to climate change among Dutch water boards. We conclude that while (inter)national water and climate change adaptation policies have called for more adaptation action at regional levels, the unequal progress across the Netherlands suggests that existing 'soft' policy measures to push for adaptation might not be sufficient to ensure progress on adaptation across all water boards.
\end{abstract}

Electronic supplementary material The online version of this article (doi:10.1007/s11269-017-1765-8) contains supplementary material, which is available to authorized users.

Robbert Biesbroek

robbert.biesbroek@wur.nl

Hans Kamperman

hans.kamperman@witteveenbos.com

1 Environmental Law and Permits PMC, Witteveen+Bos, Leeuwenbrug 8, Deventer 7411 TJ, The Netherlands

2 Public Administration and Policy Group, Wageningen University \& Research, Hollandseweg 1, Wageningen $6706 \mathrm{KN}$, The Netherlands 
Keywords Climate change adaptation $\cdot$ Netherlands $\cdot$ Water policy $\cdot$ Water boards $\cdot$ Water management plans

\section{Introduction}

Adapting to the impacts of climate change on water systems will be crucial for highly vulnerable countries such as the Netherlands. With a total of $41,543 \mathrm{~km} 2$ and more than 17 million inhabitants (CBS 2017), the Netherlands is a small and densely populated country that is vulnerable to the impacts of climate change for two main reasons. First, the Netherlands is a low-lying country situated on the delta of the rivers Rhine, IJssel and Meuse. About $24 \%$ of the country is below sea-level and without water defenses, approximately $60 \%$ of the country is vulnerable to flooding from the sea or the rivers (OECD 2014). Second, with the current setting the capacity for freshwater supply is limited, making fresh water a precious commodity in the near future (OECD 2014). In addition, extreme precipitation, river flooding, changing river discharge, availability of fresh water for consumption and irrigation, sea level rise, and salt water intrusion are among the main climatic impacts expected in the next decades (Kabat et al. 2009).

For centuries, the Netherlands has invested to manage the experienced loss and damages of flooding and to reduce the risks of the most vulnerable areas and population groups (Havekes et al. 2015). In the past, many of these decisions were based on historical climate and hydrological data (Ludwig et al. 2014; Veraart et al. 2014). More recently, many planned and proactive adaptations are proposed by the Dutch government to manage and prevent future impacts on the water system. The national government, through Rijkswaterstaat, collaborates closely with regional water authorities, the so-called water boards. These water boards are functionally decentralized governmental institutions responsible for the regional and local water system, including managing water defenses, water quantity and quality control and ensuring navigable waterways (Havekes et al. 2015; Restemeyer et al. 2017). These water boards are now also expected to play an important role in adapting their water systems to future impacts of climate change (Government 2009).

New institutional arrangements such as the Delta Commissioner, Delta Law and Delta Fund were recently created to ensure coherent and consistent climate change adaptation across all governmental levels (Vink et al. 2013; Termeer et al. 2017). The recently adopted Dutch National Adaptation Strategy (2016) further emphasizes the coordinating role of the Dutch governments and the importance of local and regional authorities to ensure timely and concrete adaptation actions (Government 2016). For more than 20 years the Dutch government has pushed regional water boards, using a variety of 'soft' policy instruments such as guidelines, subsidies, networking and resource support, to integrate climate change concerns and adaptation measures in their decision making.

Although there is anecdotal evidence that some water boards are in fact adapting (Vink et al. 2013; Boezeman et al. 2014), there is no systematic and comprehensive understanding if and how Dutch water boards are adapting to climate change and whether or not progress in the Netherlands as a whole is being made. This is largely because there are currently hardly any methodologies for systematic tracking of adaptation policy progress. Understanding policy progress on adaptation is however vital, particularly when considering the 20 years of national policy attention to climate change and the considerable investments of time, energy and resources in planning for adaptation by the national government. 
The aim of this paper is therefore to examine progress of climate change adaptation of all Dutch water boards for the period 2005-2016, and reflect on the method of tracking adaptation policy. With the rapid developments in climate change adaptation policy across levels and scales, it is important to further develop and improve methods and tools to systematically track policy progress, as is for example advocated in the Paris Agreement (2015) (Magnan and Ribera 2016) and by many national governments (Bours et al. 2015). To our knowledge this is the first attempt of a longitudinal study to systematically track climate change adaptation policy progress in the water sector at the regional scale. This paper will therefore not only advance the development of systematic adaptation tracking tools and methods but also provide crucial insights in the current state of adaptation in a forerunner country to allow for policy relevant and evaluative questions about whether or not the Dutch water boards are making enough progress to adapt to climate change and what can be done to improve progress.

In Section 2 we elaborate the operationalization of our approach to collect and analyze data on how water boards are adapting. Section 3 presents the results of our analysis followed by a discussion and conclusion in sections 4 and 5 , respectively.

\section{Methodological Framework for Measuring Adaptation Progress of Water Boards}

Systematically tracking adaptation policy over time and across contexts is no easy process as many conceptual, methodological and empirical issues need to be addressed (Ford et al. 2015). Tracking policy change requires first and foremost a consistent and comparable definition of adaptation and comprehensive and coherent data sources to conduct the analysis (Ford and Berrang-Ford 2016). In this study we define adaptation as the intentional actions taken by water boards to adapt to the projected impacts of climate change. Hence we capture adaptation actions when they are framed as such by the water boards (Dupuis and Biesbroek 2013), which is consistent with other adaptation policy tracking studies (Lesnikowski et al. 2016).

To systematically analyze the water management plans we built our conceptual and methodological framework on the work of Lesnikowski et al. (2011), who analyze different levels and types of adaptation action in order to characterize and compare adaptation efforts among the Annex I countries that submitted their National Communications to the UNFCCC.

\subsection{Selection and Collection of the Data}

We make use of the water management plan documents as these strategic policy documents provide the long term goals and concrete instruments water boards propose to use in the next six years. The Dutch Water Act (2009) requires all water boards to develop a water management plan and provide specific guidance, thereby providing a comprehensive and coherent data source across all 23 water boards, see supplementary material 1 . The water management plan contains strategic and concrete measures and actions needed for the development, operation and protection of national and regional water. The plans also include the allocation of functions to the waters (e.g. recreation, waterways, flood plains), the way in which management will be carried out, and an overview of the financial resources needed (Water Act 2009). Any efforts of water board's adaptation to climate change should be included in the water management plan, although this is no formal requirement under the Dutch water law. The water management plans provide important insights about how adaptation is positioned on 
the political agenda and is a crucial step in understanding the institutional environment within which adaptation is being implemented.

The first water management plans in our analysis were published from 2005 onwards when climate change adaptation became a topic of interest through the Motion Lemstra in the Dutch Senate that raised the issue of climate change adaptation explicitly on the political agenda in the Netherlands (Biesbroek et al. 2014). The most recent water management plans are adopted in 2016 and cover the water board's policies until 2021. In total three periods of water management plans were gathered and analyzed (2005-2010; 2010-2015; 2016-2021).

As result of the continuous reforms in the Dutch water boards, some water boards merged during the period under study. We therefore used the water boards that existed in December 2015. Consequently, for some water boards there are two plans under consideration so we used the average of both plans for the quantitative analysis. Using existing databases, online searches and emails to the water boards, we collected 71 water management plans (93\%). We were unable to retrieve some early plans, even after repetitious requests made to the water boards.

\subsection{Data Extraction and Analysis}

To assess the progress, we developed a content analysis codebook based on Lesnikowski et al. (2011) that is designed around two main categories: vulnerabilities to climate change and level and types of adaptation (see supplementary material 1).

First, to classify the vulnerabilities to climate change to which water boards are adapting, we started with the vulnerabilities described in the article of Lesnikowski et al. (2011) and adjusted based on a review of the policy and scientific literature on the main vulnerabilities of the Dutch water system (PBL 2015). The analysis revealed the following vulnerability categories: different types of floods, droughts and water quality and groundwater, storm surges, extreme heat, runoff or erosion and sea level rise. When no specific vulnerability for adaptation is described it was labelled as "unspecified". Multiple entries were used when a water management plan included more than one vulnerability.

Second, we distinguished three levels and types of adaptation: recognition, groundwork and adaptation action (Lesnikowski et al. 2011). Recognition refers to the recognized need to take action because of climate change impacts and vulnerabilities, but when no plans are implemented or steps are being taken to prepare for the impacts on the water system (Lesnikowski et al. 2011). The recognition level can be subdivided in three types: recognition of the impacts and vulnerabilities, recognition of the need to act now, and recognition of the need to act later. The second level of adaptation is groundwork, which refers to the initiatives to prepare for or inform about possible adaptation responses (Berrang-Ford et al. 2014). This level includes four types of groundwork: adaptation research, development of conceptual tools, impact and vulnerability assessments or provision of policy recommendations. Finally, the concrete and actual actions on the ground to increase resilience of the water system and the affected communities to vulnerabilities associated with climate change were identified as adaptation action (Berrang-Ford et al. 2014). At this level we distinguished six types of adaptation action: financial support of autonomous adaptation, infrastructure and technology, organizational development, public awareness and outreach, regulation and surveillance and monitoring (see also Biagini et al. 2014).

For each water management plan we coded for the targeted vulnerabilities as well the level of action (recognition, groundwork or adaptation action) and type of action (the subdivisions at 
the different levels). A detailed description of the variables is provided in the codebook (supplemental material 1). To extract and analyze the data from the water management plans we used Atlas.ti 7.0. This allowed us to capture the frequency of the reported action in the water management plans, therefore providing insights in the adaptation policy output density for each of the water management plans in each time period. The data was extracted and coded and the codebook as well as preliminary findings were discussed among the authors to ensure coding and data interpretation reliability.

\subsection{Calculating Adaptation Initiative Index Score (AII)}

To assess progress over time and compare across water boards, we calculated the Adaptation Initiatives Index (AII) score for each of the water boards based on the methods developed by Berrang-Ford et al. (2014). We weighted the scores for each of the above mentioned categories to differentiate between the relative importance of different vulnerabilities and adaptation actions as is proposed by Berrang-Ford et al. (2014). To make a distinction between the targeted vulnerabilities that fall within the responsibilities of the water boards, we differentated between two groups of vulnerability. Category 1 vulnerabilities include droughts, floods, water quality and groundwater nuisance which are legal responsibilities of the water board and as such we weighted the score with $\times 0.5$. The Category 2 vulnerabilities reflects those for which the water board is not directly responsible such as extreme heat, runoff and erosion, sea level rise, storm surges and the category "other". Here we weighted the score with $\times 0.1$. In line with other tracking studies, we also differentiated in level of adaptation action scores: adaptation action scores were weighted with $\times 2$, groundwork scores were weighted with $\times 1.5$ and recognition scores were weighted with $\times 1$ to reflect the distinction between adaptation actions that directly improve resilience to climate change, the preparatory actions (groundwork) and recognition of climate change. In addition, we calculated the scores for the three adaptation levels based on the maximum scores a water board could receive for each adaptation type. This means, for example, that for adaptation actions a maximum of six scores is calculated because we identified six adaptation action types, see Section 2.1. This leads to the following formulas for calculating the different adaptation actions:

- Recognition: $1 *(($ ToV\#cat $1 * 0.5)+($ ToV\#cat $2 * 0.1))$

- Groundwork types: $1.5 *(($ ToV\#cat1 $* 0.5)+($ ToV\#cat $2 * 0.1))$

- Adaptation action types: $2 *(($ ToV\#cat $1 * 0.5)+($ ToV\#cat $2 * 0.1))$

In the above formulas ToV\#cat 1 captures the total number of category 1 vulnerabilities for the specific adaptation type, with a score ranging between 0 and 4 vulnerabilities. ToV\#cat 2 captures the number of category 2 vulnerabilities for the specific adaptation type, with a score ranging for $0-5$ vulnerabilities.

The aggregated scores form the AII. The maximum score that a water management plan can achieve is 47.5 points, with 30 points for the adaptation action level, 15 points for groundwork and 2.5 points for the recognition level. We included an example of calculating the AII score in supplementary material 1 . The maximum adaptation index score is only possible if all vulnerabilities and adaptation actions are implemented, which is of course unlikely to happen due to policy choices for specific adaptation actions and the likelihood that the combination of these actions might create (unwanted) redundancy (Kamperman 2016). It is therefore not the goal to assess progress towards the maximum score, but rather assess changes over time and 
across contexts between the water boards. Our results do not necessarily say anything about whether or not water boards are implementing the correct or wrong activities, nor does it mention the quality of the set of adaptation initiatives adopted (Kamperman 2016).

\subsection{Interviews with Water Board Officials}

To contextualize the findings from the content analysis and understand why differences occur (or not) across time and between water boards, we selected three water boards based on the calculated AII scores to conduct interviews. During these interviews with officials responsible for the design and or implementation of the most recent water management plan, specific questions were asked about the perspective of the water board about if and how water boards should adapt to climate change, the impacts and vulnerabilities of climate change they recognize and experience, the knowledge about how water boards could adapt, and how they include climate change adaptation in their water management plan. Interviewees were also asked to reflect on the score they received from our analysis and reflect on the underlying causes of the possible changes we observed when comparing scores over time and across contexts.

\subsection{Limitations of the Methodological Approach}

Systematic coding of qualitative data is an appropriate and frequently used approach for comparing policies and plans across spatial and temporal scales, but there are recognized limitations for the methodology used in this study. First of all, the water management plans are strategic plans and analyzing them only allows us to identify the general trends of climate change adaptation policy reported by water boards. We recognize that there will be a difference in what water boards report in their water management plans and what they actually implement so we are cautious to make any inferences about the quality of the policy of individual water boards. Moreover, what water boards report in their water management plans does not necessarily reflect all the policy activities water boards employ. However, how adaptation is placed on the political agenda is an important step for ensuring implementation and therefore a crucial measurement when considering adaptation policy progress. Second, the 2016-2021 plans mainly had a conceptual status and might be subjected to changes due to final rounds of consultations. Most plans were, however, readily available and it can be expected that the final plans would not deviate too much from the final versions. Third, the scores to weight different adaptation initiatives is based on previously studies, however, it should be noted that this normative weighting is debatable. However, since we use a standardized approach over time, our findings do inform us about certain patterns between water boards over time. Given these limitations, the findings of this study show general trends, spread and changes in the reported policy output of climate change adaptation policy initiatives by all the Dutch water boards over time. Adopting this approach necessarily meant sacrificing depth for breath.

\section{Results}

We identified 1247 unique climate change adaptation initiatives in the 71 water management plans of the 23 water boards in the three time periods under analysis. This section describes the main findings of the study. 


\subsection{Floods and Droughts are the Most Reported Vulnerabilities}

Across the three time periods, and for all the three levels of adaptation (recognition, groundwork and concrete action), the main vulnerabilities targeted are floods (rural and urban) and droughts (for agriculture, nature, navigation, and urban areas).

Our analysis showed a strong increase in the number of recognition initiatives for these vulnerabilities between the 2005-2010 and the 2010-2015 time periods. However, overall the picture shows a general increase across the different time periods for all levels and vulnerabilities. There is limited attention for vulnerabilities other than flooding and drought, but this could be expected given the severity of these existing vulnerabilities for the Netherlands. At the recognition level, for example, some initiatives regarding extreme heat and water quality related issues are mentioned for the 2016-2021 time period. Vulnerabilities as a result of sea level rise and storm surges are mentioned from 2010 to 2015 onwards. However, no initiatives for groundwater nuisance and runoff or erosion are found, for example. Groundwork level shows the same picture, with some increase in initiatives for water quality and extreme heat in the 2016-2021 time period. A negligible number of initiatives are found with regard to groundwater nuisance, runoff or erosion and storm surges. Finally, at adaptation action level, the initiatives to address flood related vulnerabilities are dominant, with little attention to droughts in urban areas and fresh water quality. The findings suggest that water boards stay close to their historical tasks and responsibilities in water management by targeting floods and droughts, and are gradually including other vulnerabilities.

\subsection{Adaptation Remains Primarily in the Recognition and Groundwork Stage}

During the three periods investigated there is an increase in the amount of climate change adaptation initiatives reported, see Fig. 1. However, adaptation remained primarily in the recognition and groundwork stage, with very few actions being reported at the concrete adaptation action level.

The number of recognition initiatives has clearly increased between 2005 and 2010 (108\%) with limited increase between 2010 and 2016. When looking more closely at the results (see Table 1), we find mainly recognition of climate change impacts and vulnerabilities (2005-2010: 83.5\%, 2010-2015: 78.4\%, and 2016-2021: 71.5\%) with limited reference to recognition of the need to act now $(4.7 \%, 9.8 \%$ and $9.7 \%$, respectively) or recognition to act later $(11.8 \%, 11.8 \%$ and $18.8 \%$, respectively).

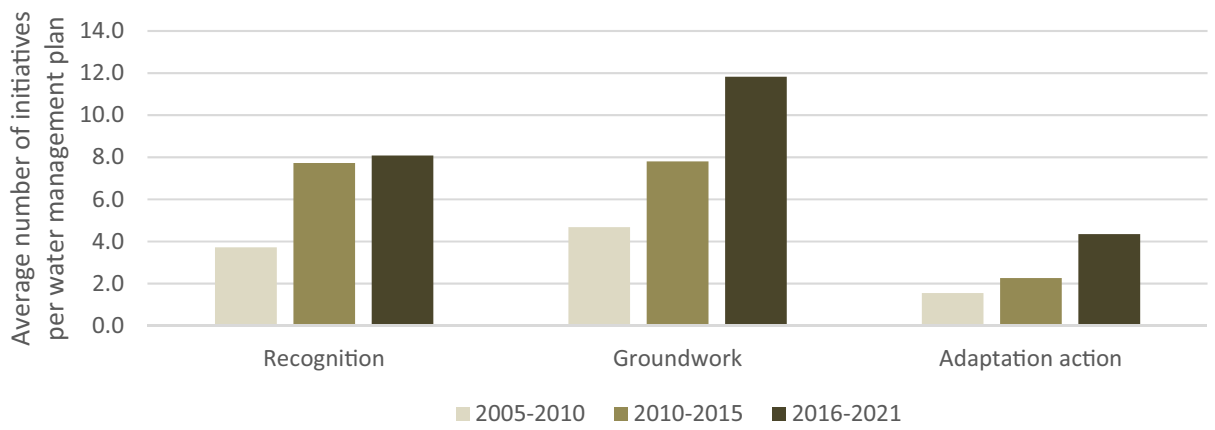

Fig. 1 Calculated average of the adaptation action, groundwork and recognition per water management plan for each of the three time periods 
Table 1 The total number of initiatives per adaptation type and the percentage of the total found adaptation initiatives for the three time periods

\begin{tabular}{lccc}
\hline Recognition & $2005-2010$ & $2010-2015$ & $2016-2021$ \\
\hline Adaptation types & & & \\
$\quad$ Impacts and vulnerabilities & $71(83.5 \%)$ & $160(78.4 \%)$ & $133(71.5 \%)$ \\
Need to act later & $10(11.8 \%)$ & $24(11.8 \%)$ & $35(18.8 \%)$ \\
$\quad$ Need to act now & $4(4.7 \%)$ & $20(9.8 \%)$ & $18(9.7 \%)$ \\
Groundwork & & & \\
Adaptation research & $8(7.8 \%)$ & $22(10.8 \%)$ & $37(13.6 \%)$ \\
Development of conceptual tools & $52(50.5 \%)$ & $73(35.8 \%)$ & $111(40.8 \%)$ \\
Impact and vulnerability assessments & $15(14.6 \%)$ & $42(20.6 \%)$ & $40(14.8 \%)$ \\
$\quad$ Provision of policy recommendations & $28(27.2 \%)$ & $67(32.8 \%)$ & $84(30.9 \%)$ \\
Adaptation action & & & $2(2.0 \%)$ \\
Financial support for autonomous adaptation & $6(17.6 \%)$ & $4(6.8 \%)$ & $52(52.0 \%)$ \\
Infrastructure and technology & $21(61.8 \%)$ & $39(66.1 \%)$ & $2(2.0 \%)$ \\
Organizational development & $0(0.0 \%)$ & $1(1.7 \%)$ & $31(31.0 \%)$ \\
$\quad$ Public awareness and outreach & $1(2.9 \%)$ & $5(8.5 \%)$ & $3(3.0 \%)$ \\
Regulation & $4(11.8 \%)$ & $6(10.2 \%)$ & $10(10.0 \%)$ \\
$\quad$ Surveillance and monitoring & $2(5.9 \%)$ & $4(6.8 \%)$ & $558(44.7 \%)$ \\
Total number of initiatives & $222(17.8 \%)$ & $467(37.4 \%)$ & \\
\hline
\end{tabular}

This suggests that while climate change is recognized as an important issue for water boards, the urgency to adapt quickly is not very prominent or missing and has not changed significantly in the period of analysis.

The most significant increase is observed at the groundwork level which shows a clear increase between the plans made in 2005 and 2010 (66\%) and between 2010 and $2016(51.3 \%)$. This suggests that water boards are increasingly preparing the ground work for the implementation of concrete climate change adaptation initiatives. More specifically, water management plans report most frequently on the development of conceptual tools (2005-2010: 50.5\%, 2010-2015: 35.8\%, 2016-2021: 40.8\%) and the provision of specific policy recommendations and guidelines $(27.2 \%, 32.8 \%$ and $30.9 \%$, respectively) to help building the capacity to implement adaptation (see Table 1). One example of a conceptual tool developed by most water boards is the three step method for managing the water system as proposed by national water policy: first ensure water retention, then consider water storage and last consider water discharge. These conceptual tools are becoming an integral part of integrated water management in the Netherlands and are considered important in the context of adapting to future climate change impacts.

Our findings also show that water management plans report an increasing number of concrete adaptation actions, but the total number of initiatives is much lower compared to recognition and groundwork. There is however an increase visible between the plans made in 2005 and 2010 (53.3\%) and between 2010 and 2016 (87.0\%). The observed increase in adaptation actions are mostly infrastructure and technology initiatives (2005-2010: 61.8\%, 2010-2015:66.1\% and 2016-2021: 52.0\%). The most recent period under analysis shows a strong increase in public awareness and outreach (31.0\% of the initiatives for 2016-2021). This is parallel to a more general trend in the Netherlands of more decentralized and bottom-up efforts by local governmental bodies and societal actors for water management and adaptation, as for example is reflected in the Dutch Delta Program (Van Alphen 2016). 


\subsection{Progress Made by Water Boards}

To determine the progress on climate change adaptation by water boards, we calculated their Adaptation Initiatives Index scores for each of the three time periods. Table 2 provides an overview of the AII scores. When averaging the scores of all water boards for each time period, we see an overall increase in reported climate change adaptation initiatives from 4.7 (2005-2010) to 7.8 (2010-2016) to 9.5 (2016-2021) across the water boards. This suggests that water boards are increasingly considering climate change adaptation in their planning for water management. However, the results show a large variability in scores between the water boards and between the time periods.

As for the changes over time, there are ten water boards for which their AII score increased more than 2 points between the first two time periods (2005-2010 and 2010-2016), three water boards for which the score did not change more than 2 points per time period, and for the others the change was less than 2 points (two water boards demonstrated a small decrease). Data was missing for three water boards which therefore did not receive a score for 20052010. Table 2 shows that especially Rivierenland scored high on climate change adaptation in their water management plans followed by Schieland en de Krimpenerwaard and Vallei en Veluwe for the first two time periods. Especially the water boards of De Stichtse Rijnlanden, De Dommel, and Rijnland scored low.

Between the two last periods (2010-2015 and 2016-2021), the score increased with more than 2 points for 11 water boards and five water boards demonstrated an increase with more than 5 points. However, Table 2 also shows that the AII scores of five water boards decreased with more than 2 points between the last two periods, with one water board showing a decrease of 6.6 points. For the other water boards the score did not change with more than 2 points. While the average score for 2016-2021 is still higher compared to 2010-2015, the variation in scores is much larger. These results suggests that some water boards made significant progress compared to the other water boards, and a number of water boards reduced their reporting of adaptation initiatives. For the most recent time period (2016-2021), Zuiderzeeland, Vallei en Veluwe en Aa en Maas scored highest with De Stichtse Rijnlanden, Delfland and Rijnland on the low end of the index.

We selected three water boards to explore and discuss the results of the AII to better understand the observed differences from the AII scores, particularly for the 2010-2015 and 2016-2021 time periods. The water board of Schieland en de Krimpenerwaard was selected because it scored among the top three water boards in the first two periods, but demonstrated a decrease for the last period. The water board of De Stichtse Rijnlanden was selected because it had a bottom three score for all three periods. The water board of Aa en Maas was selected because it had a relatively low score for the first two periods but showed a large increase for 2016-2021.

The interviewees all argued that climate change is already affecting their water boards and that particular events had already occurred, particularly extreme precipitation events. The experience of events combined with climate change research, for example through the Delta Program, was considered an important driver in all three water boards for starting to include adaptation more explicitly in the water management plans. When asked to reflect on the causes for the scores in the AII, interviewees from Schieland en de Krimpenerwaard (high score, but decreasing) argued that the first two reporting periods were used to put adaptation on the political agenda and that the water management plan played a crucial role in this process. However, as there currently is sufficient political attention, the most recent water management plan reflects the strategy to integrate or 'mainstream' adaptation into specific implementation programs and budgets. Adaptation is, according to the interviewees, "business as usual" and 
Table 2 Adaptation Initiatives Index Scores for the water management plans per water board for the three time periods with an indication for the top three (dark grey) and bottom three (light grey)

\begin{tabular}{|c|c|c|c|}
\hline Water Boards & 2005-2010 & 2010-2015 & 2016-2021 \\
\hline Aa en Maas & 3.8 & 6.3 & 12.3 \\
\hline Amstel, Gooi en Vecht & 4.9 & 5.9 & 8 \\
\hline Brabantse Delta & N/A & 4.5 & 7 \\
\hline De Dommel & 4.3 & 3.8 & 4.9 \\
\hline De Stichtse Rijnlanden & 1.9 & 3.8 & 3.3 \\
\hline Delfland & 4.5 & 8 & 4.2 \\
\hline Fryslân & N/A & 7.3 & 5 \\
\hline Groot Salland & N/A & 5.1 & 10.4 \\
\hline Hollandse Delta & 0 & 7.3 & 6.9 \\
\hline Hunze en Aas & 3.7 & 9.3 & 5.9 \\
\hline Noorderzijlvest & 3.8 & 7.4 & 4.8 \\
\hline Reest en Wieden & 5.2 & 6.8 & 10.4 \\
\hline Rijn en IJssel & 2.9 & 6.9 & 11.9 \\
\hline Rijnland & 1.6 & 5 & 4.7 \\
\hline Roer en Overmaas & 6.1 & 6.5 & 10.8 \\
\hline Scheldestromen & 3.6 & 5.5 & 5.9 \\
\hline Schieland en de Krimpenerwaard & 6.9 & 9.3 & 7.4 \\
\hline Vallei en Veluwe & 7.5 & 7.5 & 14.4 \\
\hline Vechtstromen & 6.3 & 7.6 & 10.4 \\
\hline Zuiderzeeland & 5.5 & 6.4 & 14.9 \\
\hline Hollands Noorderkwartier & 5.6 & 8.4 & 9 \\
\hline Peel en Maasvallei & 6.5 & 4.9 & 10.8 \\
\hline Rivierenland & 10.1 & 13.4 & 6.8 \\
\hline Average score per time period & 4.7 & 7.8 & 9.5 \\
\hline Standard error & 0.51 & 0.44 & 0.69 \\
\hline
\end{tabular}

N/A: The three water boards of Brabantse Delta, Fryslân, and Groot Salland do not have an AII score for the period 2005-2010 because their water management plan were not available

therefore initiatives are no longer reported in the water management plans, nor explicitly framed as adaptation in other policy documents. The low scoring water board De Stichtse Rijnlanden acknowledges that their water management plan remains rather generic when it comes to adaptation. Although the interviewees argued that they are implementing some 
concrete adaptation actions, they agreed that much of the work is still in the recognition and ground work stages, and that much progress can still be made. Finally, the interviewee from the water board of Aa en Maas argued that they have become increasingly aware of the impacts of climate change and have started to broaden their approach for climate change adaptation beyond the traditional flood and drought vulnerabilities by including for example heat stress. In addition, the collaboration in the Delta Program allowed for specific adaptation actions for adapting to extreme precipitation.

\section{Discussion}

This study is the first attempt to systematically analyze how Dutch water boards are progressing in developing and implementing climate change adaptation initiatives at the regional level. The results of this study demonstrate an increasing attention to climate change adaptation across the water management plans of Dutch water boards over time. This finding is similar to other adaptation tracking studies in different fields such as public health (Austin et al. 2016) or adaptation more generally (Lesnikowski et al. 2016), which also found an increase in adaptation initiatives. However, by adopting this systematic tracking approach we find more critically that adaptation is currently still at the recognition or groundwork level and progress is being made mostly when it comes to groundwork initiatives for adaptation. All water boards recognize the main vulnerabilities with regard to climate change and have developed for example conceptual tools to guide adaptation. However, reported progress on actual climate change adaptation actions are much less visible although we find an increase in reported activities on infrastructure and technology and, in more recent plans, public awareness and outreach. This is perhaps surprising given that the Netherlands is often hallmarked in the literature as a forerunner when it comes of climate change adaptation in the water sector. Our results suggest, however, that water boards focus on vulnerabilities that are well known to and an integral part of their water management tasks, including addressing various types of floods and droughts. Despite more than 20 years of policy efforts by the national government through soft policy instruments, very limited policy initiatives are considered to newly emerging water risks, including impacts on water quality, extreme heat, storm surges, groundwater nuisance and to some extent sea level rise. The step to concrete adaptation initiatives is still lagging behind, both for the traditional themes as well as more recently emerging water management issues in the Netherlands. Combining different 'hard' and 'soft' modes of implementing adaptation initiatives will be important to consider in order to strengthen adaptation in the Dutch water sector.

Surprisingly, a number of water boards show signs of rapid decrease in their AII scores. This can be explained by a number of possible causes. First, this might be because of the methodology used in this study. As discussed in the methods section, there are limitations to the quality of the data used and reporting bias can be expected when it comes to implementing adaptation measures as not all measures will be reported in the strategic plans and specific operational plans for adaptation might exist. However, given that we systematically collected and analyzed the data for all the water management plans for different time periods, it is surprising to see the differences across time periods. Second, there will be differences in vulnerability to climate change between the management areas of the water boards. These are not captured in their AII scores. Some water boards face many climate change risks and thus will be more active to adapt to the risks compared to water boards with a low vulnerability. Arguably, not all vulnerabilities might be relevant for each water board, but the AII used in this study is not sensitive to specific vulnerabilities. The 
actual assessment of how risks and vulnerabilities align with the adaptation policy initiatives requires further refinement of the framework. Third, our analysis might actually capture the process of dismantling and/or reframing of specific adaptation policy initiatives. Although climate change adaptation has been at the forefront of many national water policy decisions, the political landscape has reframed the discourse on climate change adaptation to long term water safety, which means "adaptation" has gradually disappeared from the political agenda (Vink et al. 2013; Biesbroek et al. 2014; Van Buuren et al. 2016), particularly in the period 2010 2012. During that time, climate change issues in the Netherlands were reframed to long term water management rather than adaptation, and water boards were forced to develop policies and measures that addressed their legally defined tasks and responsibilities. This did not include a holistic, but rather a narrow understanding of adaptation. Finally, as suggested by the interviewee from Schieland en de Krimpenerwaard, lower AII scores might be the result of successful adaptation where adaptation is being integrated or mainstreamed into existing institutional and policy frameworks and therefore no longer explicitly framed as "climate change adaptation", therefore rendering it impossible to track using our policy tracking methodology. This is a crucial finding from this study as it necessitates further reflection on the methods to capture the shift from high political attention reported in water management plans to concrete mainstreaming of adaptation actions implemented in the water sector. This is one of the next grand challenge for adaptation policy tracking research.

Applying the tracking methodological framework in this study offers several other new avenues for research. Whilst our study used the criteria suggested by Ford and Berrang-Ford (2016) for collecting and analyzing data for tracking purposes, we argue that additional data sources such as interviews and additional document analysis might help to overcome some of the challenges described by Ford and Berrang-Ford (2016) and earlier policy tracking studies, specifically when it comes to interpreting the research findings. In addition, although the water boards are by far the most important actors in Dutch water management there are many other non-governmental actors from different levels and scales that play a role in climate change adaptation in the Netherlands. Although this research aimed to capture adaptation policy initiatives, future research could complement our study by including other levels and actors.

Second, this study has assessed progress by counting the number of policy initiatives on climate change adaptation, as most policy tracking studies currently do. Although offering interesting results, it does not allow for much analysis on the quality of the policy initiatives included in the water management plans, nor inform about the implementation of the actions. Future tracking studies should pay additional attention to analytically more complex issues of how to track the quality of what water boards are doing, for example by assessing not only the density (frequency) of policy initiatives, as done in this study, but also their intensity (content), see Shafferin et al. (2015) for a proposal of such an approach. This would allow for a more refined comparative analysis of the progress water boards are actually making. Systematic tracking of the impact of adaptation policy (i.e. implementation), however, is currently not possible due to challenges of attribution and system complexity (Hupe et al. 2014).

Finally, our findings mirror the increased efforts of the Dutch national government in pushing for implementation of climate change adaptation, by creating an enabling governing environment, a process that many counties are currently engaged in. To assess whether or not governmental investments are successful, efficient and whether or not governments have learned are important question governments face in the context of climate change adaptation, but this is complicated due to the lack of a baseline assessment of the climate change risks as well as missing baselines of adaptation policy initiatives that allow us to assess changes over 
time and between contexts. Although the Netherlands has a large number of climate change impact studies (i.e. PBL 2015), detailed water impacts and vulnerability assessments for all water boards in the Netherlands currently do not exist, making it difficult, if not impossible to effectively monitor the impact of specific policy initiatives. This finding is not only a crucial challenge in the Dutch context; many countries are currently struggling to monitor, report and evaluate their adaptation initiatives, both in developed and developing countries (Bours et al. 2015). Stricter and more elaborate reporting guidelines on adaptation initiatives might help governments to assess how water boards are adapting to the impacts of climate change which allows to answer political questions if such progress is enough and fast enough.

\section{Conclusion}

Our study represents a first attempt to systematically analyze the progress Dutch water boards make in adapting to the impacts of climate change by comparing three sequential water management plans for each water board. Our findings demonstrate that water boards are making progress with regional climate change adaptation but efforts remain at the recognition and groundwork level such as developing impact and vulnerability assessments, development of conceptual tools and provision of policy recommendations to guide adaptation. If concrete adaptation action initiatives are described in the water management plans they almost exclusively occur in regards to infrastructure and technology and more recently, policy instruments related to public awareness and outreach. We conclude that while (inter)national water and climate change adaptation policies have called for more action at regional levels, including water boards, the unequal progress across the Netherlands suggests that existing 'soft' policy instruments to push for adaptation actions might not be sufficient to ensure progress on adaptation in the Netherlands and perhaps elsewhere.

Acknowledgements We would like to thank Dr. Erik van Slobbe for his contributions to this work and Andrew Tanabe for edits, comments and suggestions on an earlier version of this paper.

Open Access This article is distributed under the terms of the Creative Commons Attribution 4.0 International License (http://creativecommons.org/licenses/by/4.0/), which permits unrestricted use, distribution, and reproduction in any medium, provided you give appropriate credit to the original author(s) and the source, provide a link to the Creative Commons license, and indicate if changes were made.

\section{References}

Austin S, Biesbroek G, Berrang-Ford L, Ford J, Parker S, Fleury M (2016) Public health adaptation to climate change in OECD countries. Int J Environ Res Public Health 13:889

Berrang-Ford L, Lesnikowski A, Poutiainen C, Barrera M, Heymann S (2014) What drives national adaptation? A global assessment. Clim Chang 124:441-450

Biagini B, Bierbaum R, Stults M, Dobardzic S, Mc Neeley S (2014) A typology of adaptation actions: a global look at climate adaptation actions financed though the global environment facility. Glob Environ Chang 25: 97-108

Biesbroek R, Termeer CJAM, Klostermann JEM, Kabat P (2014) Analytical lenses on barriers in the governance of climate change adaptation. Mitig Adapt Strateg Glob Chang 19(7):1011-1032

Boezeman D, Vink MJ, Leroy P, Halffman W (2014) Participation under a spell of instrumentalization? Reflections on action research in an entrenched climate adaptation policy process. Crit Pol Stud 8(4):407-426

Bours D, McGinn C, Pringle P (eds) (2015) Monitoring and evaluation of climate change adaptation: a review of the landscape. Wiley Periodicals Inc New Directions for Evaluation (147) 
CBS (2017) StatLine database. Statistics Netherlands. www.cbs.nl. Accessed 13 June 2017

Dupuis J, Biesbroek R (2013) Comparing apples and oranges? The dependent variable problem in comparing and evaluating climate change adaptation policies. Glob Environ Chang 23(6):1476-1487

Ford J, Berrang-Ford L (2016) The 4Cs of adaptation tracking: consistency, comparability, comprehensiveness, coherency. Mitig Adapt Strateg Glob Chang 21(6):839-859

Ford J, Berrang-Ford L, Biesbroek G, Araos M, Austin S, Lesnikowski A (2015) Adaptation tracking for a post2015 climate agreement. Nat Clim Chang 5(10):967-969

Government (2009) Nationaal Waterplan 2009-2015. In: The Hague: Ministerie van Verkeer en Waterstaat; Ministerie van Volkshuisvesting, Ruimtelijke Ordening en Milieubeheer; Ministerie van Landbouw. Voedselkwaliteit, Natuur en

Government (2016) Aanpassen met ambitie - Nationale klimaatadaptatiestrategie 2016 (NAS). Ministery of Infrastructure and the Environment, The Hague

Havekes H, Koster M, Dekking W, Uijterlinde R, Wensink W, Walkier R (2015) Water governance. The Dutch water authority model. Dutch Water Authorities, The Hague

Hupe P, Hill M, Nangia M (2014) Studying implementation beyond deficit analysis: the top-down view reconsidered. Public Policy and Administration 29(2):145-163

Kabat P, Fresco LO, Stive MJF, Veerman CP, Van Alphen JSLJ, Parmet BWAH, Hazeleger W, Katsman CA (2009) Dutch coasts in transition. Nat Geosci 2(7):450-452

Kamperman H (2016) Climate change adaptation at the Dutch water boards: a comparative quantitative research of how Dutch water boards are adapting to climate change (2005-2020). Wageningen University, Wageningen

Lesnikowski A, Ford J, Berrang-Ford L, Paterson J, Barrera M, Heymann S (2011) Adapting to health impacts of climate change: a study of UNFCCC annex I parties. Environ Res Lett 6(4):044009

Lesnikowski A, Ford J, Biesbroek G, Berrang-Ford L, Heymann J (2016) National-level progress on adaptation. Nat Clim Chang 6:261-264

Ludwig F, Van Slobbe E, Cofino W (2014) Climate change adaptation and integrated water resources management in the water sector. J Hydrol 518:235-242

Magnan AK, Ribera T (2016) Global adaptation after Paris. Science 352(6291):1280-1282

OECD (2014) Water governance in the Netherlands: fit for the future? OECD Publishing, Paris, OECD studies on Water

PBL (2015) Adaptation to climate change in the Netherlands-studying related risks and opportunities (no 1632). Bilthoven, Netherlands Environmental Assessment Agency (PBL)

Restemeyer B, van den Brink M, Woltjer J (2017) Between adaptability and the urge to control: making longterm water policies in the Netherlands. J Environ Plan Manag 60(5):920-940

Shafferin A, Sewerin S, Seubert S (2015) Toward a comprehensive measure of policy output. Policy Studies Journal 43(2):257-282

Termeer CJAM, Dewulf A, Biesbroek GR (2017) Transformational change: governance interventions for climate change adaptation from a continuous change perspective. J Environ Plan Manag 60(4):558-567

Van Alphen J (2016) The Delta Programme and updated flood risk management policies in the Netherlands. Journal of Flood Risk Management 9(4):310-319

Van Buuren MW, Vink MJ, Warner JF (2016) Constructing authoritative answers to the 'climate crisis' in the Netherlands. Policy analysis and the dynamic interplay of puzzling and powering and framing. Journal of Comparative Policy Analysis 18(1):70-87

Veraart JA, van Nieuwaal K, Driessen PPJ, Kabat P (2014) From climate research to climate compatible development: experiences and progress in the Netherlands. Reg Environ Chang 14(3):851-863

Vink M, Boezeman D, Dewulf A, Termeer C (2013) Changing climate, changing frames: Dutch water policy frame developments in the context of a rise and fall of attention to climate change. Environ Sci Policy 30:90-101

Water Act (2009) Waterwet. Hoofdstuk 4 Plannen, §2 Regionale waterplannen, Artikel 4.6 